\title{
THERAPEUTIC SERIOUS GAME DESIGN GUIDELINES FOR STIMULATING COGNITIVE ABILITIES OF CHILDREN WITH SPEECH AND LANGUAGE DELAY
}

\author{
${ }^{1}$ Nadia Akma Ahmad Zaki, ${ }^{2}$ Tengku Siti Meriam Tengku Wook \\ ${ }^{3}$ Kartini Ahmad \\ ${ }^{I}$ Faculty of Art, Computing and Creative Industry \\ Sultan Idris Education University \\ Perak, Malaysia \\ ${ }^{2}$ Faculty of Information Science and Technology \\ Universiti Kebangsaan Malaysia \\ ${ }^{3}$ Faculty of Health Sciences \\ Universiti Kebangsaan Malaysia
}

nadiaakma@fskik.upsi.edu.my;tsmeriam@ukm.edu.my;kart@ukm.edu.my

\begin{abstract}
The creation of an effective therapeutic serious game (TSG) is highly dependent upon its design and the fundamental knowledge of the users. Furthermore, the TSG is designed for a purpose to the users by incorporating the needs of the users in all design components. Although numerous studies have been conducted on guidelines for designing serious games, to date, studies on the specific TSG's design guidelines for stimulating the cognitive ability of children with speech and language delay (CSLD) has yet to be comprehensively studied. Therefore, this study focuses on the set of design guidelines for the development of TSG for CSLD, specifically on cognitive stimulation. The TSG design guidelines in this paper are derived through the study of relevant literature, and best practices gained from interviews with experts in the area of speech pathology. These guidelines would be useful for researchers and game designers to design TSG for CSLD focusing on cognitive stimulation.
\end{abstract}

Keywords: Design guidelines, therapeutic, serious games, cognitive stimulation, children with speech and language delay. 


\section{INTRODUCTION}

Language difficulties affecting children are common developmental problems encountered by clinicians, and concern is often voiced by parents (Buschmann et al., 2008; Parakh, Parakh, Bhansali, \& Gurjar, 2012). In general, a child is considered to have speech and language delay (CSLD) if his or her speech and language development is substantially below the expectation at their age level (Hotonu, Aldous, \& Schafer-Dreyer, 2011; Lawrence \& Bateman, 2013). It has been reported that five to eight per cent of preschool children have this disorder and it often persists into their school years (Nelson, Nygren, Walker, \& Panoscha, 2006). This disorder is three times more common in boys compared to girls (Hawa \& Spanoudis, 2014; Hotonu et al., 2011; Parakh et al., 2012). CSLD are a heterogeneous group with different individual and environmental characteristics; comprising of developmental delays of speech and language, expressive language disorder, receptive language disorder, hearing loss, intellectual disabilities, mental retardation, delayed growth, down-syndrome, autism, cerebral palsy, Attention Deficit Hyperactivity Disorder (ADHD) and physical speech problems (Hotonu et al., 2011; Lawrence \& Bateman, 2013; McLaughlin, 2011; Nelson et al., 2006; Parakh et al., 2012).

Past studies have shown that language difficulties often co-occur with cognitive delays (Jansen et al., 2013). Moreover, several studies have also shown that CSLD are at risk for poor early literacy skills development, which may be associated with increased difficulty with reading (Lafferty, Gray, \& Wilcox, 2005; Lawrence \& Bateman, 2013; McLaughlin, 2011; Shetty, 2012). Hence, this leads to below par school performance and a lower IQ, that may persist into young adulthood (Nelson et al., 2006). If this disorder continues till adulthood, these children are at risk of experiencing learning problems, stress, isolation from the community, and may have problems to secure jobs due to their communication impairment (Nelson et al., 2006). As cognition and language are intrinsically related in development and function, it is important for CSLD to improve their cognitive development. Existing works have highlighted the potential of cognitive stimulation for enhancing children's cognitive ability and providing good results in the development over the years (Bonnier, 2008; Hackman, Farah, \& Meaney, 2010). Children with less stimulation are nearly six times more likely to have language delay as compared to children with more stimulation (Malhi, Sidhu, \& Bharti, 2014). They are recommended to undergo therapy that focuses on linguistic and cognitive ability, as the chances for them to heal would be much higher (Law, Garrett, \& Nye, 2003; Lawrence \& Bateman, 2013; Schuit, Segers, Balkom, \& Verhoeven, 2011). Thus, CSLD with low cognitive ability require 
cognitive stimulation to enable them to think, give suggestions, understand, and remember things that are happening around them.

Serious games show great potential in stimulating the cognitive abilities of different target audiences including children (Ahmad Zaki, Tengku Wook, $\&$ Ahmad, 2015). The use of serious games are well accepted among the population with cognitive disabilities because they feel safe and comfortable exploring the virtual world and obtaining immediate feedback without feeling anxious of social rejection (Tomé et al., 2014). Nowadays, the introduction of serious games in the therapeutic context or therapeutic serious games (TSG) is promising and can be used for improving one's health through therapy and rehabilitation (Durango, Carrascosa, Gallud, \& Penichet, 2015; Horne-Moyer, Moyer, Messer, \& Messer, 2014). The combination of therapeutic content and gaming elements with therapeutic objectives can create new, motivating and engaging therapeutic environments (Wrzesien et al., 2014). Thus, TSG can be used as an alternative potential tool to stimulate and induce a general improvement of CSLD's cognitive abilities.

In order to successfully stimulate the CSLD's cognitive abilities through TSG, these games must be well designed to effectively and efficiently deliver training. Result based on the preliminary thematic analysis of the semistructured interviews with experts, indicate that CSLD face major difficulties in developing cognitive abilities such as memory, attention, perception, problem-solving, decision-making, language, learning and reasoning. In addition, they also lack preverbal and motor skills (Ahmad Zaki, Tengku Wook, \& Ahmad, 2017). Therefore, TSG design guidelines must take into account the fundamental knowledge of the needs and preferences of the user, identify cognitive difficulties in performing the task, as well as ensure that therapeutic adherence would be above par and the therapy will succeed (Boot et al., 2013). The TSG design guidelines should also follow the common user interface design principles and support the children's use and understanding through appropriate consideration of their cognitive development. At the same time, the user must feel at ease with the technology, and be willing and motivated in accepting new concepts in learning new skills.

Guidelines are a set of important concepts and rules for designing a user interface. Design guidelines also are based on human psychology; focusing on how people perceive, learn, reason, remember, and convert intention into action (Johnson, 2010). Although there have been numerous studies on guidelines for designing effective educational serious games (Ahmad, Rahim, \& Arshad, 2015; Carvalho et al., 2015; Mariais, Michau, \& Pernin, 2010; 
Roungas \& Dalpiaz, 2016), no study has been conducted on specific guidelines and best practices on the development of effective TGS in order to stimulate the cognitive ability. Hence, it is important to establish specific guidelines. Thus, the aim of this study is to investigate and outline the development of a set of design guidelines for TGS focusing on cognitive stimulation and targeting CSLD aged four to seven years old.

\section{LITERATURE REVIEW}

\section{Existing Research Guidelines}

Few studies have been conducted on producing guidelines for normal children and children with special needs, serious games and stimulating cognitive processes. The study done by Chiasson and Gutwin (2005) lists a catalogue of design principles for children's technology that are oriented towards the needs of designers to adapt interfaces on how children naturally behave, to accommodate based on children's developing skills and knowledge, and to create products that are enjoyable for children. The resulting catalogue is based on the development of children and is categorized into three main areas: cognitive, physical, and social/emotional. Meanwhile, a study done by Tran and Subrahmanyam (2013) presents guidelines on children's informal computer experiences to maximize their potential benefit for children's development such as academic, cognitive and social skills. In 2014, Straker et al. (2014) presented a set of evidence-based guidelines regarding the wise use of electronic games (e-games) by children. This guideline was prepared for different potential stakeholders such as children, parents, professionals and the e-game industry. The author also found evidence that used games as a supplement to aid intervention for special populations and rehabilitation. (Chiasson \& Gutwin (2005); Straker et al. (2014); Tran \& Subrahmanyam (2013) however, only provided a generic list of guidelines for children and did not furnish readers with a list of information for children of a particular age.

Children of different ages have enormous differences in preferences, abilities, level of skills and experiences with technologies; thus an age-appropriate guideline is important to accurately meet their needs (Chiasson \& Gutwin, 2005; Gelderblom \& Kotzé, 2008). The study carried out by Gelderblom and Kotzé (2008) lists a useful framework of design guidelines grounded in the psychological theory of development for children aged five to eight years. Meanwhile, a study by Tengku Wook and Salim (2013) lists an age- 
appropriate guideline for web application graphics design, which targets children aged three to eleven years. Besides that, a study done by Lieberman et al. (2009) discovered principles of game design that are more developmentally appropriate and beneficial for children aged 3 to 6 years. However, studies by Gelderblom \& Kotzé (2008); Lieberman et al. (2009); Tengku Wook \& Salim (2013) did not take into account children aged four to seven years. Moreover, none of these studies (Chiasson \& Gutwin, 2005; Gelderblom \& Kotzé, 2008; Lieberman et al., 2009; Straker et al., 2014; Tengku Wook \& Salim, 2013; Tran \& Subrahmanyam, 2013) considered the use of serious games.

Nevertheless, studies conducted by Høiseth et al. (2013) and Szczesna et al. (2012) produced design guidelines for serious games specifically for children. Research done by Høiseth et al. (2013), presented design guidelines for healthcare games and applications for toddlers (children aged 1-3 years) while Szczesna et al. (2012) presented main guidelines for designing psychology serious games based on the cognitive behaviour techniques for pre-school children. Even though studies by Høiseth et al. (2013) and Szczesna et al. (2012) have produced design guidelines for serious games targeting children, the studies were not specifically for CSLD. However, there is a study that produced a set of guidelines for children with speech delay but its main focus was on designing software to facilitate multisyllabic speech production (Hailpern, Harris, La Botz, Birman, \& Karahalios, 2012). There are studies conducted on children with special needs (Abdul Aziz, Wan Ahmad, \& Hashim, 2016; De La Guía, Lozano, \& Penichet, 2015). The study by Abdul Aziz et al. (2016) presented the design for mobile application proposed to assist children with autism to acquire numerical skills. Meanwhile, a study by De La Guía et al. (2015) focused on educational games with the aim of enhancing and stimulating the learning process of children with ADHD.

The design implications for various kinds of cognitive processes have been discussed by Sharp et al. (2011). The authors believe the way an interface is designed greatly influences how people perceive, attend, learn, remember and solve their problems. Meanwhile, a large and growing body of literature has investigated the use of serious games to stimulate cognitive abilities (Imbeault, Bouchard, \& Bouzouane, 2011; Lányi, Brown, Standen, Lewis, \& Butkute, 2012; Tomé et al., 2014; Vasconcelos et al., 2012), but these games are designed for Alzheimer patients, those with intellectual disabilities, and senior citizens. Nevertheless, in a study by Imbeault et al. (2011), some guidance for achieving the optimal experience in training sessions were proposed. Another research article that presented a list of recommended design principles and 
the potential of serious games as an effective learning and engaging resource is by Guía et al. (2014). Meanwhile, Vasconcelos et al. (2012), listed ten rules for a gaming platform for senior citizens that promotes quality-of life and well-being by incorporating cognitive training mechanisms. All these studies (Guía et al., 2014; Imbeault et al., 2011; Lányi et al., 2012; Tomé et al., 2014; Vasconcelos et al., 2012) have capitalized on the advantages of serious games in stimulating the cognitive abilities of different target audiences and purposes.

\section{The Cognitive Development of Children}

Nowadays, digital game play is an integral aspect of children's lives, providing a window into applied cognitive development and a continually expanding context in which children spend their leisure and learning time, thus, considering that developmental research especially in cognitive development can contribute to effective game design (Blumberg \& Fisch, 2013). Cognitive development refers to the progressive and continuous growth of attention, perception, memory, learning, language, decision-making, and problemsolving; where information is received, transformed, stored, and used to solve problems and process languages (Herr, 2008; Singleton \& Shulman, 2014).

Many theories have been proposed regarding how children learn or adapt to their environment and how cognitive development works (see (Shaffer \& Kipp, 2014)). One of the most influential thinkers in this area was Jean Piaget. Piaget created highly influential theories on the stages of mental development among children, becoming a leading figure in the field of cognitive theory and developmental psychology. He used four basic concepts, namely schema, assimilation, adaptation and equilibrium to elaborate upon the activity process of an individual's cognitive structure (Singleton \& Shulman, 2014). At the centre of Piaget's theory is the principle that cognitive development occurs in a series of four distinct universal stages, each characterized by increasingly sophisticated and abstract levels of thought (Santrock, 2014; Shaffer \& Kipp, 2014). The first distinct stage is sensorimotor (from birth to 2 years), followed by preoperational (2 to 7 years), concrete operational (7 to 11 years) and lastly, formal operational (begins in adolescence and spans into adulthood).

As this study focuses on CSLD between four to seven years old, the preoperational stage will be the focus of this study. However, the sensorimotor stage is also taken into account as even at age four (according to chronological age), their cognitive development is slower than normal children. Barak and 
Schiffman (1981) and Hoyer and Roodin (2009) argue that chronological age is no longer presumed to be an automatic predictor of factors such as health, intelligence and mental capacity.

According to Piaget, at the stage of sensorimotor, infants construct an understanding of the world by coordinating sensory experiences such as seeing and hearing with physical movements and actions. They begin to use their senses to understand and interact with the environment. At the end of this stage, they can produce complex sensory motor patterns and use primitive symbols. Piaget also recognized the adaptive significance of imitation; the ability to reproduce a modelled activity that was witnessed at some point in the past and understand the concept of preservation of objects (object permanence). Object permanence is the realization that objects continue to exist when they are no longer visible (Santrock, 2014; Shaffer \& Kipp, 2014).

In the preoperational stage, children begin to represent the world with words, images and drawings. They also gain the ability to represent mentally an object that is not present. This ability is known as the symbolic function. Besides that, children at this stage are likely to assume that unfamiliar objects, which move on their own, have lifelike qualities, which is known as animism. They also typically assume that others share their points of view. According to Piaget, the condition is regarded as egocentrism. Egocentric attitude means they see and understand the environment through their own perspective and always think that others have the same perception, reaction and perspectives. This is because they are still unable to accept the views of others. The thinking of the children is based on intuitive understanding of the objects that depend on the characteristics of the apparent and the real. This feature is also referred to as a perception-bound thought because children are unable to think logically. Judgments are made based on perceptual appearances, and focus on a single aspect of a situation when seeking answers to a problem. Children at this stage have yet to master the process of irreversibility and reversibility; they cannot reminisce the way an object or a situation prior to the change of the situation or the object (Santrock, 2014; Shaffer \& Kipp, 2014).

\section{METHODOLOGY}

Regardless of what kind of game is designed or what technology is used for the gameplay, there are general best practices for designing a game for a specific target user. The use of a specific design guideline will contribute to an even higher game quality and assist the developer by ensuring the user interface 
remains consistent across all applications on any one platform (Barendregt \& Bekker, 2004). Thus, to achieve the research goal, the process is divided into two parts: (a) to conducting a literature review focusing on the existing guidelines, designing principles for children's technology including serious games for children focusing on the area of cognitive stimulation, and reviewing literature on the theory of cognitive development; and (b) to conducting empirical work involving semi-structured interviews with experts in the area of speech pathology on the best practice for designing game activities.

Literature review was conducted from established journals and books. The results are discussed in the literature review section that focuses on the existing guidelines, design principles for children's technology including serious games for children focusing on cognitive stimulation, and the theory of cognitive development.

\section{Semi-structured Interviews}

Besides the literature review, it is also vital to develop a strong multidisciplinary collaboration between engineers and clinicians (Rizzo \& Kim, 2005). As mentioned in Rizzo and Kim (2005) the collaboration should help to address and overcome objections raised by clinicians regarding the use of technological innovations and allay fears that by doing so, would influence both the patienttherapist relationship, and the therapist's ability to control the treatment. In addition, in making the treatment or intervention more accessible to patients, it could also entail in enhancing the level of engagement or persuasiveness of the technology. Therefore, it is important to consider professional experience in handling and interacting with CSLD during therapy sessions. Thus, the second part of this study obtains suggestions and best practices from the professionals' perspectives in dealing with CSLD, and consequently assisting in the development of TSG.

This work method is similar to the one conducted by Ahmad Zaki et al. (2017), but this study used a different approach in analysing data. The interview method was chosen because it is an effective method for obtaining in-depth data pertaining to particular role or a set of tasks (Devi, Sen, \& Hemachandran, 2012; Maguire, 2001). Based on Nielsen (1993) and Devi et al. (2012), at least five respondents and more are needed for the interview. Therefore, semistructured interviews were conducted with six experts in the field of speech pathology. the interviews were based on a series of fixed questions with a 
scope that could be expanded based on their responses. All the respondents were speech therapists from the private and public sectors. Out of the six interviews, four were conducted face-to-face and the two were done over the phone, with an estimated time of between 20-30 minutes per respondent. The interviews were audio-recorded to be re-played and annotated later at a more appropriate pace. The data obtained from the respondents were transcribed into written form to be analysed. The content analysis approach was used for analysing the interview data (Lazar, Feng, \& Hochheiser, 2010). This approach involves examination of the transcript of the interviews for pattern usage, such as frequency of terms and co-occurrences that may provide indications of the importance of various concepts and relationships between them.

\section{RESULTS AND DISCUSSION}

By using the triangulation method, a number of design guidelines were identified that could be adopted from previous studies as well as from the interviews with the experts. Based on the analysis of past studies, some consideration was given to choosing the design guidelines based on technology appropriate to the psychological development of children (Chiasson \& Gutwin, 2005; Gelderblom \& Kotzé, 2008; Lieberman et al., 2009; Straker et al., 2014; Tengku Wook \& Salim, 2013; Tran \& Subrahmanyam, 2013). The design guidelines for serious games for children (Høiseth et al., 2013; Szczesna et al., 2012) were also analysed, and referred to the design guidelines for children with special needs (Aziz, Ahmad, \& Zulkifli, 2015; De La Guía et al., 2015; Hailpern et al., 2012). Nevertheless, the design implications that had been specifically generated for various kinds of cognitive processes (Rogers et al., 2011) were considered, and as well as the design guidelines for serious games to stimulate cognitive ability that were for a different target audience (Guía et al., 2014; Imbeault et al., 2011; Lányi et al., 2012; Tomé et al., 2014; Vasconcelos et al., 2012). Based on Piaget's theory of cognitive development, the children's cognitive abilities and skills in the sensorimotor and preoperational stages (Santrock, 2014; Shaffer \& Kipp, 2014) were also taken into account. Based on the analysis of these studies, a list of 77 recommended design guidelines for adequate development of serious games targeting cognitive stimulation of CSLD was established, which are outlined in Table 1. Nevertheless, 24 suggestions and best practices from the interview with experts with regard to the method of working with CSLD during a gaming activity were collected. The results of the suggestions and best practices are listed in Table 2 . 


\section{Table 1}

\section{Design Guidelines Gained from the Literature Review}

\begin{tabular}{llllll}
\hline \multicolumn{3}{c}{ Item } & \multicolumn{1}{c}{ Author/s } \\
\hline $\begin{array}{l}\text { Design simple layouts to increase } \\
\text { concentration. }\end{array}$ & user $\begin{array}{l}\text { (Lányi et al., 2012; Tomé et al., 2014 } \\
\text { (de La Guía et al., 2015) }\end{array}$
\end{tabular}

2. Design interfaces that promote recognition rather (Rogers et al., 2011) than recall.

3. The interface should provide additional hidden information, supportive scaffolding and guidance to help children remember how to accomplish tasks that are just beyond their reach.

4. A well-designed game should captivate players' interest to perform tasks on their own initiative and not for the reward.

5. The game should be designed according to the (Tomé et al., 2014) cultural environment of the player.

6. Design interfaces that encourage exploration.

(Rogers et al., 2011)

7. Design interfaces that constrain and guide users to select appropriate actions when initialising learning.

8. Avoid cluttering the interface with too many (Rogers et al., 2011) information.

9. Implement a fixed game window, to prevent (Tomé et al., 2014) users from resizing it unintentionally.

10. Game should provide relevant play activities and set at the right children development level to suit their ability.

(Rogers et al., 2011)

(Abdul Aziz et al., 2016; Chiasson \& Gutwin, 2005; de la Guia, Lozano, \& R. Penichet, 2013; Høiseth et al., 2013; Lieberman et al., 2009; Szczesna et al., 2012; Tomé et al., 2014)

11. The icons and other graphical representations should be visually meaningful to the children.

(Chiasson \& Gutwin, 2005; Rogers et al., 2011)

12. Bordering and spacing of grouping icons or information will be easier to perceive and locate items.

(Rogers et al., 2011; Tomé et al., 2014)

13. Due to the diffculty involved in abstract thinking, the game should use symbols and images to represent real-life situations.

(Chiasson \& Gutwin, 2005;

Gelderblom \& Kotzé, 2008; Tomé et al., 2014) 


Item
14. The icons/images should be large and spaced
appropriately to avoid wrong selections and to
help users who have fine motor skill difficulties.
15. Use familiar symbols/icon in the manner
commonly used

16. Ensure each feature is qualified and functions accordingly.

17. To exit the game, a sign or indication needs to be provided.

18. Include images with particular names to improve retention of information.

19. Games should provide clear, repeatable demonstrations.

20. Use simple text fonts and large fonts.

21. Text should be readable and distinguishable from the background.

22. Minimize the number and avoid dense blocks of text on the screen.

23. Maintain a consistent use of colour on objects or text, which have the same meaning.

24. Colours should be in harmony with the overall interface, while ensuring sufficient contrast between foreground and background colours.

25. Use clear instructions.

26. Instructions should be presented in an ageappropriate format.

27. Instructions and buttons should be clearly displayed and must always be in the same place.

28. Use verbal messages to acquire the attention, enthusiasm and concentration of the user.

29. Sound should be audible and distinguishable for players to understand what they represent.

30. The game must provide performance feedback to show the children their progress and achievement.
Author/s

(Chiasson \& Gutwin, 2005; Rogers et al., 2011; Tomé et al., 2014)

(Abdul Aziz et al., 2016; Tengku Wook \& Salim, 2013; Tomé et al., 2014)

(Lányi et al., 2012; Tengku Wook \& Salim, 2013)

(Tengku Wook \& Salim, 2013)

(Tomé et al., 2014)

(Lieberman et al., 2009)

(Tengku Wook \& Salim, 2013)

(Rogers et al., 2011; Tengku Wook \& Salim, 2013)

(Tengku Wook \& Salim, 2013; Tomé et al., 2014)

(Rogers et al., 2011; Tengku Wook \& Salim, 2013)

(Lányi et al., 2012; Tengku Wook \& Salim, 2013; Tomé et al., 2014)

(Tengku Wook \& Salim, 2013)

(Chiasson \& Gutwin, 2005)

(Tengku Wook \& Salim, 2013; Tomé et al., 2014)

(De La Guía et al., 2015; de la Guia et al., 2013)

(Rogers et al., 2011)

(Lieberman et al., 2009; Szczesna et al., 2012; Tomé et al., 2014) 
Item

31. Provide instant and adequate feedback throughout the game.

32. The feedback should use sounds, specifically spoken language for children with communication diffculties targeting both vocabulary and comprehension levels.

33. Users should be immediately rewarded for taking the correct action using elements that have potential as meaningful rewards.

34. Interactive encouragement and assistance should be incorporated.

35. The language should be simple, clear and direct.

36. Use the children's native language.

37. The game should allow users to go back to a previous stage in the game especially for users who have information processing and/or memory difficulties.

38. The game must be relatively slow and not require the use of many controls.

39. Encourage a moderate amount of time spent for playing games.

40. Games should support the children's social interaction in specific activities and tasks with their friends and family.

41. The game needs to be very straightforward, simple and easy to learn to avoid confusion.

42. Use minimal interface items, as more complex items diminish the acceptance of the game.

43. The game should offer a varying range of fun activities to encourage learning and help maintain players' interest.

44. Provide game treatment-relevant play activities that can excite and stimulate the imagination of the users.

45. Large screens and mobile devices like tablets can be transported and played anywhere, allowing the player to play easily, engaging him/her with a visual experience in a comfortable position and environment.
Author/s

(Chiasson \& Gutwin, 2005; Imbeault et al., 2011; Tomé et al., 2014; Vasconcelos et al., 2012)

(Tomé et al., 2014)

(Høiseth et al., 2013; Tomé et al., 2014; Vasconcelos et al., 2012)

(de la Guia et al., 2013; Gelderblom \& Kotzé, 2008; Lieberman et al., 2009)

(Tomé et al., 2014)

(Tomé et al., 2014)

(Lányi et al., 2012; Tomé et al., 2014)

(Tomé et al., 2014)

(Straker et al., 2014; Tran \&

Subrahmanyam, 2013)

(Høiseth et al., 2013; Lieberman et al., 2009; Straker et al., 2014; Tran \& Subrahmanyam, 2013)

(de la Guia et al., 2013; Imbeault et al., 2011; Lieberman et al., 2009)

(Tomé et al., 2014)

(Lieberman et al., 2009; Szczesna

et al., 2012; Tomé et al., 2014;

Vasconcelos et al., 2012)

(Høiseth et al., 2013; Straker et al., 2014; Szczesna et al., 2012)

(Vasconcelos et al., 2012)

(continued) 
Item

46. Touch screen technology allows easy interactions for children whose coordination is yet to be fully developed.

47. When manipulating objects in the game, it is more realistic to drag-drop objects to select and move them, rather than just clicking on them.

48. Avoid games with aggressive and violent themes.

49. Create characters, which are similar to the child to provide the player a sense of identity and model what the child could do in his/her own life.

50. If the players cannot overcome certain challenges, the game should provide extensive opportunities for them to rehearse and apply new skills.

51. Games should maintain a balance between success and challenge.

52. The game should convey functional knowledge and provide the players with opportunities to develop useful skills or practise newly acquired skills.

53. The game should be capable of estimating the cognitive abilities of children by providing tasks that they are capable of performing.

54. There should be a clear goal to maintain the focus of the users and engage them with the game.

55. Avoid cluttering user's memories with complicated procedures for carrying out tasks.

56. Dynamically link concrete representations and abstract concepts to facilitate the learning of complex material.

57. Use simple and memorable functions at the interface for computational aids intended to support rapid decisions that occur while on the move.

58. In order to apply problem-solving skills in the game, the same sequence in the real world must be followed.

59. In the decision-making process, players should be guided step-by-step.

60. Use the cause and effect paradigm and reverse actions in the game activities.
Author/s

(Chiasson \& Gutwin, 2005; Hailpern et al., 2012; Vasconcelos et al., 2012)

(Gelderblom \& Kotzé, 2008; Tomé et al., 2014)

(Tran \& Subrahmanyam, 2013)

(Lieberman et al., 2009; Szczesna et al., 2012; Tomé et al., 2014)

(Lieberman et al., 2009)

(Tomé et al., 2014).

(Gelderblom \& Kotzé, 2008; Straker et al., 2014; Tomé et al., 2014)

(Gelderblom \& Kotzé, 2008;

Imbeault et al., 2011)

(Vasconcelos et al., 2012)

(Rogers et al., 2011)

(Rogers et al., 2011; Santrock, 2014; Shaffer \& Kipp, 2014)

(Rogers et al., 2011)

(Tomé et al., 2014)

(Tomé et al., 2014)

(Gelderblom \& Kotzé, 2008;

Santrock, 2014; Shaffer \& Kipp, 2014; Tomé et al., 2014) 


\section{Item}

61. The child's information can appear on the screen to stimulate the interest of the child.

62. Simple game activities can trigger logical thinking.

63. Children lack understanding on the concept of transformation, and focus on the current state of the object rather than the dynamic changes.

64. The game should apply the classification of objects based on similarities in shapes, colours and sizes.

65. Rewards should be consistent and available at all activity levels.

66. Provide entertainment by embedding fun element to maintain children's interest and positive attitude, promote intrinsic motivation and allow children to take breaks from the main task.

67. Provide animated on-screen agents/character to guide, encourage, or entertain children during the task.

68. Use repetitive elements to keep the children's interest.

69. The game should transport the player in a psychological state of flow.

70. Provide simple, uncluttered option menus for children for easier choices in the interface.

71. Minimize the delay in response to engage the children with the interaction, the game, and learning.

72. The game should incorporate both sound and images to ensure effective learning process.

73. The repetition process helps the children to memorize the lesson learned.

74. The consistency feature is important to avoid children's confusion and frustration.

75. The game should provide a challenge and stimulate the curiosity of the children.

76. The game should offer different difficulty levels to suit the players' ability.

77. Interfaces should be strongly visual, avoiding text as much as possible and reducing cognitive load.
Author/s

(Lieberman et al., 2009)

(Santrock, 2014; Shaffer \& Kipp, 2014)

(Santrock, 2014; Shaffer \& Kipp, 2014)

(Santrock, 2014; Shaffer \& Kipp, 2014)

(Chiasson \& Gutwin, 2005)

(Chiasson \& Gutwin, 2005; Szczesna et al., 2012)

(Chiasson \& Gutwin, 2005)

(Høiseth et al., 2013)

(Szczesna et al., 2012)

(Hailpern et al., 2012)

(Hailpern et al., 2012)

(Abdul Aziz et al., 2016)

(Abdul Aziz et al., 2016)

(Abdul Aziz et al., 2016)

(De La Guía et al., 2015)

(De La Guía et al., 2015; Lieberman et al., 2009; Szczesna et al., 2012)

(Chiasson \& Gutwin, 2005) 


\title{
Table 2
}

\section{Suggestions and Best Practices from the Speech Therapists' Perspective}

\author{
Items \\ 1. Real graphics should be employed in the game. \\ 2. An appropriate colour scheme should be used. \\ 3. An easily readable default font size should be used. \\ 4. The game should incorporate performance feedback. \\ 5. Demonstration on how to play the game should be included. \\ 6. Clear instructions should be demonstrated throughout the game. \\ 7. The players are encouraged to play individually or in pairs. \\ 8. The children's fine motor skills must be taken into account. \\ 9. Players should be rewarded when they have won the game. \\ 10. The time used to play games should be controlled/ restricted. \\ 11. The games should not exhibit any characteristics of violence. \\ 12. While playing, the children should be accompanied by an adult. \\ 13. Game activities should be set at the right child developmental level. \\ 14. Scoring initiators should exist in these games for monitoring purposes. \\ 15. Repetition and practice are essential for the consolidation of learning. \\ 16. Contextual aspects in the game like help/guidance/ tips should be included. \\ 17. The games are suitable to be played on a large screen, or on portable and lightweight \\ gadgets.
}

18. The games need to encourage children to recognize objects, actions, and events around them.

19. The games must require two-way interaction that can also help speech-language development.

20. It is worth paying attention to the focal length and duration of exposure of children to the screen.

21. The game should be developed in the children's native language, namely the Malay language.

22. Vocabulary used in the game should be modified according to the child's level of comprehension.

23. A separate volume control or mute button should be provided for speech and background music.

24. The game must have high adaptability in that it can be adjusted according to the performance of the children.

To produce a set of TSG design guidelines for stimulating the cognitive process of CSLD, the design guidelines gained from the literature review in Table 1 and the results analysis of the interview with experts in the area of speech 
pathology in Table 2 were taken into account. The method from Tengku Wook and Salim (2013) was adapted to conduct a comparison and coordination study between both the tables. The best practices from the experts in Table 2 was the main foundation of this study and each item in the Table 1, which has the same meaning, was merged. Figure 1 shows the coordination process of design guidelines.

\begin{tabular}{|c|c|}
\hline \multicolumn{2}{|c|}{ Design guidelines gained from the literature review } \\
\hline 1.Design simple layouts to increase user concentration. & 41. The game needs to be very straightforward, simple and easy to learn to avoid confusion. \\
\hline 2. Design interfaces that promote recognition rather than recall. & 42. Use minimal interface items, as more complex items diminish the acceptance of the game. \\
\hline $\begin{array}{l}\text { 3. The interface should provide additional hidden information, supportive scaffolding } \\
\text { and guidance to help children remember how to accomplish tasks that are just }\end{array}$ & $\begin{array}{l}\text { 43. The game should offer a varying range of fun activities to encourage learning and help } \\
\text { maintain players' interest. }\end{array}$ \\
\hline & 44. Provide game treatment-relevant play activities that can excite and stimulate the \\
\hline 4.A well-désigneed gamè should captivate players' intererest to perform tasks on their & imagination of the users. \\
\hline own initiative and not for the reward. & 45. Large screens and mobile devices like tablets can be transported and played anywhere, \\
\hline $\begin{array}{l}\text { 5. The game should be designed according to the cultural environment of the player. } \\
\text { 6. Design interfaces that encourage exploration. }\end{array}$ & $\begin{array}{l}\text { allowing the player to play easily, engaging him/her with a visual experience in a } \\
\text { comfortable position and environment. }\end{array}$ \\
\hline $\begin{array}{l}\text { 7.Design interfaces that constrain and guide users to select appropriate actions } \\
\text { when initialising learning. }\end{array}$ & $\begin{array}{l}\text { 46. Touch screen technology allows easy interactions for children whose coordination is } \\
\text { yet to be fully developed. }\end{array}$ \\
\hline$g$ the interface with too many information. & 47. When manipulating objects in the game, it is more realistic to drag-drop objects to \\
\hline xed game window, to prevent users from resizing it unintentionally. & select and move them, rather than just clicking on them. \\
\hline de relevant play activities and set at the right children & 48. Avoid games with aggressive and violent themes. \\
\hline jit their ability. & 49. Create characters, which are similar to the child to provide the player sense of identity \\
\hline ther graphical representations should be visually meaningful & and moc \\
\hline 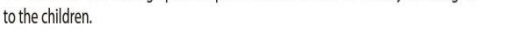 & certain challenges, the game should provide extensive \\
\hline 12. Bor & id apply new skills. \\
\hline and locat & 51. Games should maintain a balance between success and challenge. \\
\hline $\begin{array}{l}\text { 13. Due to the difficulty involved in abstract thinking, the game should use symbols } \\
\text { and images to represent real-life situations. }\end{array}$ & $\begin{array}{l}\text { 52. The game should convey functional knowledge and provide the players with } \\
\text { opportunities to develop useful skills or practice newly acquired skills. }\end{array}$ \\
\hline $\begin{array}{l}\text { 14. The icons/images should be large and spaced appropriately to avoid wrong } \\
\text { selections and to help users who have fine motor skills difficulties. }\end{array}$ & $\begin{array}{l}\text { 53. The game should be capable of estimating the cognitive abilities of children by providing } \\
\text { tasks that they are capable performing. }\end{array}$ \\
\hline 15. Use familiar symbols/icon in the manner commonly used & 54. There should be a clear goal to maintain the focus of the users and engage them with \\
\hline $\begin{array}{l}\text { ccordingly. } \\
\text { e provided. }\end{array}$ & $\begin{array}{l}\text { the game. } \\
\text { 55. Avoid cluttering user's memories with complicated procedures for carrying out tasks. }\end{array}$ \\
\hline nprove retention of information. & 56. Dynamically link concrete representations and abstract concepts to facilitate the learning \\
\hline table demonstrations. & \\
\hline 20. Use simple & 57. Use simple and memorable functions at the interface for computational aids intended to \\
\hline 21. Text should be readable and distinguishable from the background. & pid decision that oc \\
\hline block of text on the screen. & ider to apply problem-solving skills in the game, the \\
\hline 23. Maintain a consistent use of colour on objects or text, which have the same meaning. & must be \\
\hline 24. Colours should be in harmony with the overall interface, while ensuring sufficient & 59. In the decision making process, players should be guided step-by-step \\
\hline contrast betwe & 60. Use the cause and effect p \\
\hline 25. Use clear instructions. & 61. The child's information can appear on the screen to stimulate interest of the child. \\
\hline 26. Instructions should be pres & 62. Simple game activities can \\
\hline $\begin{array}{l}\text { 27. Instructions and buttons should be clearly displayed and must always be in the } \\
\text { same place. }\end{array}$ & $\begin{array}{l}\text { 63. Children lack understanding on the concept of transformation, and to focus on the current } \\
\text { state of the object rather than the dynamic changes. }\end{array}$ \\
\hline $\begin{array}{l}\text { 28. Use verbal messages to acquire the attention, enthusiasm, and concentration of } \\
\text { the user. }\end{array}$ & $\begin{array}{l}\text { 64. Game should apply the classification of objects based on similarities in shapes, colours and } \\
\text { sizes. }\end{array}$ \\
\hline $\begin{array}{l}\text { 29. Sound should be audible and distinguishable for players to understand what } \\
\text { they represent. }\end{array}$ & $\begin{array}{l}\text { 65. Rewards should be consistent and available in all activities levels. } \\
\text { 66. Provide entertainment by embedding fun element to maintain children's interest and }\end{array}$ \\
\hline $\begin{array}{l}\text { 30. The game must provide performance feedback to show the children their progress } \\
\text { and achievement. }\end{array}$ & $\begin{array}{l}\text { positive attitude, promotes intrinsic motivation and to allow children to take breaks from the } \\
\text { main task. }\end{array}$ \\
\hline 31. Provide instant and adequate feedback throughout the game. & 67. Provide animated on-screen agents/character to guide, encourage, or entertain children \\
\hline 32. The feedback should use sounds, specifically spoken language for children with & hetask. \\
\hline communication difficulties targeting both vocabulary and comprehension levels. & 68. Use repetitive elements to keep the children's interest. \\
\hline $\begin{array}{l}\text { 33. Users should be immediately rewarded for taking the correct action using elements } \\
\text { that have potential as meaningful rewards. }\end{array}$ & $\begin{array}{l}\text { 69. The game should transport the player in a psychological state of flow. } \\
\text { 70. Provide simple, uncluttered option menus for children for easieier choiceses in the interface. }\end{array}$ \\
\hline $\begin{array}{l}\text { 34. Interactive encouragement and assistance should be incorporated. } \\
\text { 35. The language should be simple, clear, and direct. }\end{array}$ & $\begin{array}{l}\text { 71. Minimize the delay in respond to engage the children with the interaction, the game, and } \\
\text { learning. }\end{array}$ \\
\hline 36. Use the children's native language. & 72. The game should incorporate both sound and images to ensure effective learning process. \\
\hline 37. The game should allow users to go back to a previous stage in the game especially & 73. The repetition process helps the children to memorize the lesson learned. \\
\hline for users who have information processing and/or memory difficulties. & 74. The consistency feature is important to avoid children's confusion and frustration. \\
\hline 38. The game must be relatively slow and not require the use of many controls. & 75. The game should provide a challenge and stimulate the curiosity of children. \\
\hline 39. Encourage moderate amount of time spent for playing games. & 76. The game should offer different difficulty levels to suit the players' ability. \\
\hline $\begin{array}{l}\text { 40. Games should support the children's social interaction in specific activities and tasks } \\
\text { with their friends and family. }\end{array}$ & $\begin{array}{l}\text { 77. Interfaces should be strongly visual, avoiding text as much as possible and reducing } \\
\text { cognitive load. }\end{array}$ \\
\hline
\end{tabular}




\begin{tabular}{|c|c|}
\hline \multicolumn{2}{|c|}{ Suggestions and Best Practices from the Speech Therapists' Perspective } \\
\hline 1.Real graphics should be employed in the game__ 13 & 14. Scoring initiators should exist in these games for monitoring purposes. \\
\hline 2.An appropriate colour scheme should be used. 24 & 15. Repetition and practice are essential for the consolidation of learning.-73 \\
\hline 3.An easily readable default font size should be used. - 21 & 16. Contextual aspects in the game like help/guidance/ tips should be included. \\
\hline 4.The game should incorporate performance feedback. 30 & 17. The games are suitable to be played on a large screen, or on portable and lightweight gadgets. - (45) \\
\hline 5.Demonstration on how to play the game should be included. & 18. The games need to encourage children to recognize objects, actions, and events around them. \\
\hline 6.Clear instructions should be demonstrated throughout the game. & 19. The game must require two-way interaction that can also help speech-language development. \\
\hline 7. The players are encouraged to play individually or in pairs. & 20. It is worth paying attention to the focal length and duration of exposure of children to the screen.-39 \\
\hline 8. The children's fine motor skills must be taken into account. 14 & 21. The game should be developed in the children's native language, namely the Malay language. - 36 \\
\hline 9. Players should be rewarded when they have won the game. & 22. Vocabulary used in the game should be modified according to the child's level of comprehension. \\
\hline 10. The time used to play games should be controlled/ restricted, 39 & 23. A separate volume control or mute button should be provided for speech and background music. \\
\hline 11. The games should not exhibit any characteristics of violence. & 24. The game must have high adaptability in that it can be adjusted according to the performance of the \\
\hline 12. While playing, the children should be accompanied by an adult. & children. \\
\hline
\end{tabular}

Figure 1. The coordination process of design guidelines.

\section{DESIGN GUIDELINES}

As a result, a revised set of design guidelines was obtained and categorized into 15 categories, namely identification with the game, interface design, layout, demonstrations, reward/encouragement, performance feedback and guidance, personalization, adaptive games and challenges, social interaction, mobility, time management/restriction, repetition and rehearsal of skills, motivation and engagement, motor skill and cognitive development.

The descriptions of the categorization are: (a) identification with the game refers to configuration of the game to parallel the user's needs (Tomé et al., 2014); (b) interface design focuses on interface elements that are easy to access, understand, and to facilitate users (Tomé et al., 2014); (c) layout focuses on appearance on the screen such as aspect of space, margins, and font type and size selection (Tengku Wook \& Salim, 2013); (d) demonstration is the process of demonstrating the visual presentations of the content (Lieberman et al., 2009); (e) reward is given in recognition of effort or achievement, while encouragement refers to the action of persuading to continue a task, support, confidence or hope (Chiasson \& Gutwin, 2005; Lieberman et al., 2009; Vasconcelos et al., 2012); (f) performance feedback and guidance refer to response on a player's achievements and progress in the game (Lieberman et al., 2009; Szczesna et al., 2012; Vasconcelos et al., 2012); (g) personalization is the process of tailoring the game to an individual user's characteristics or preferences (Lieberman et al., 2009; Szczesna et al., 2012); (h) adaptive games and challenges represent the adaptability of the difficulty according to the skill of the player, in order to increase playability and enjoyment (Lieberman et al., 2009; Szczesna et al., 2012); (i) social interaction involves the formation of relationships with others (Chiasson \& Gutwin, 2005; Lieberman et al., 2009); 
(j) mobility is the ability to move or be moved freely and easily (Vasconcelos et al., 2012); (k) time management/restriction is the process of planning and controlling the amount of time spent (Tran \& Subrahmanyam, 2013); (1) repetition and rehearsal of skills are the processes that facilitate repetitive actions (Høiseth et al., 2013; Lieberman et al., 2009); (m) motivation and engagement refer to the user's degree of attention, curiosity, interest, optimism and passion when using the game (Chiasson \& Gutwin, 2005; Szczesna et al., 2012); (n) motor skill is the physical development that deals with the development of fine and gross motor skills as well as coordination (Chiasson \& Gutwin, 2005; Hailpern et al., 2012); and (o) Cognitive development addresses the mental and intellectual growth of a child that may assist in the designing of technologies to extend the users' capabilities and compensate their weaknesses (Chiasson \& Gutwin, 2005; Rogers et al., 2011). These categories can ease and help developers to plan and develop well-designed games. The results are listed in Table 3 below:

\section{Table 3}

\section{TSG Design Guidelines for Stimulating Cognitive of CSLD}

\begin{tabular}{|c|c|}
\hline Categories & Design Guidelines \\
\hline $\begin{array}{l}\text { 1. Identification } \\
\text { with the game }\end{array}$ & $\begin{array}{l}\text { (a) The game should be developed in the children's native language. } \\
\text { (b) The games should not exhibit any aggressive characteristics and } \\
\text { violent themes. } \\
\text { (c) The game should be designed according to the cultural } \\
\text { environment of the player. } \\
\text { (d) The game needs to be very straightforward, simple and easy to } \\
\text { learn to avoid confusion. } \\
\text { (e) Provide game treatment-relevant play activities that can excite } \\
\text { and stimulate the imagination of the users. }\end{array}$ \\
\hline
\end{tabular}

2. Interface design (a) Design interfaces that encourage exploration.

(b) Design simple layouts to increase user concentration.

(c) Avoid cluttering the interface with too much information.

(d) Use familiar symbols/icons in the manner commonly used.

(e) To exit the game, a sign or indication needs to be provided.

(f) Ensure each feature is qualified and functions accordingly.

(g) Include images with particular names to improve retention of information.

(h) Design interfaces that promote recognition rather than recall, and be visually strong.

(i) The consistency feature is important to avoid children's confusion and frustration. 


\begin{tabular}{l} 
Categories Design Guidelines \\
\hline (j) Implement a fixed game window, to prevent users from resizing \\
it unintentionally. \\
(k) Maintain a consistent use of colour on objects or texts, which \\
have the same meaning. \\
(l) Provide simple, uncluttered option menus for children for easier \\
choices in the interface. \\
(m) The icons and other graphical representations should be visually \\
(n) Interfaces should be strongly visual, avoiding text as much as \\
(o) Use minimal interface items, as more complex items diminish \\
the acceptance of the game. \\
(p) Design interfaces that constrain and guide users to select \\
appropriate actions when initialising learning. \\
(q) Colours should be in harmony with the overall interface, while \\
ensuring sufficient contrast between foreground and background \\
colours.
\end{tabular}

3. Layout

(a) Use simple large text fonts.

(b) Clear instructions should be demonstrated throughout the game.

(c) Instructions should be presented in an age-appropriate format.

(d) Text should be readable and distinguishable from the background.

(e) Minimize the number and avoid dense block of texts on the screen.

(f) Use verbal messages to acquire the attention, enthusiasm, and concentration of the user.

(g) Instructions and buttons should be clearly displayed and must always be in the same place.

(h) Sound should be audible and distinguishable for players to understand what they represent.

(i) Bordering and spacing, and grouping icons or information will be easier to perceive and locate items.

(j) A separate volume control or mute button should be provided for speech and background music.

4. Demonstrations a) Games should provide clear, repeatable demonstrations.

b) Demonstration on how to play the game should be included.

5. Reward/

a) Interactive encouragement and assistance should be incorporated. encouragement

b) Rewards should be consistent and available in all activity levels.

c) Contextual aspects in the game like help/ guidance/ tips should be included.

d) Users should be immediately rewarded for taking the correct action using elements that have potential as meaningful rewards. 


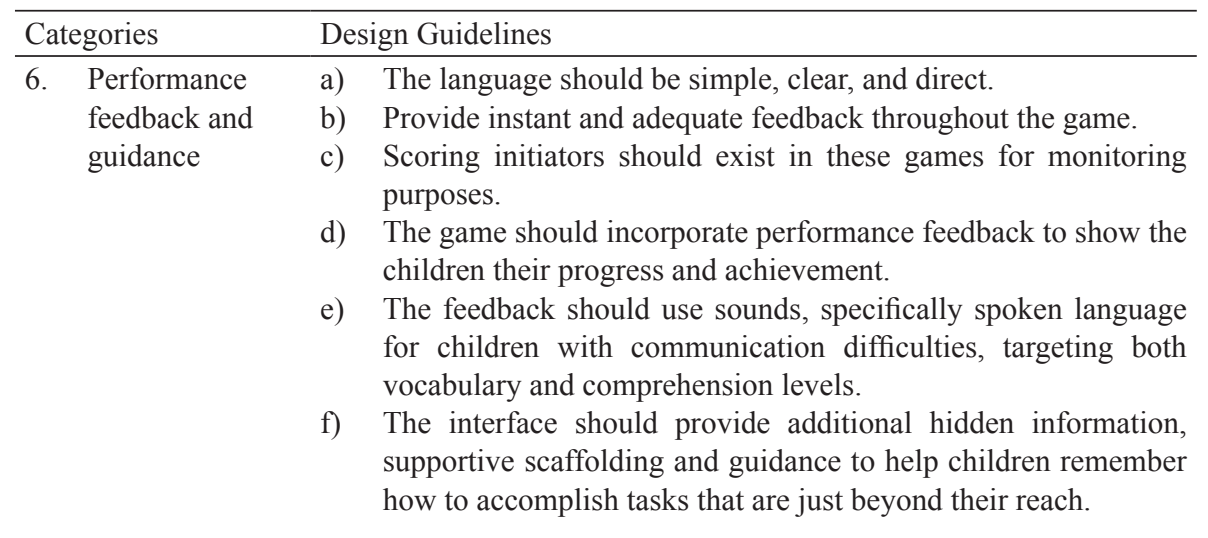

7. Personalization a) The child's information can appear on the screen to stimulate the interest of the child.

b) Create characters, which are similiar to the child to provide the player a sense of identity and model what the child could do in his/her own life.

8. Adaptive games a) Games should maintain a balance between success and challenge. and challenges b) The game should offer different difficulty levels to suit the players' ability.

c) The game should provide a challenge and stimulate the curiosity of the children.

d) The game must have high adaptability in that it can be adjusted according to the performance of the children.

9. Social interaction

a) While playing, the children should be accompanied by an adult.

b) The game must require a two-way interaction that can also help speech-language development.

c) Games should support the children's social interaction in specific activities and tasks with their friends and family.

10. Mobility

a) Large screens and mobile devices like tablets can be transported and played anywhere, allowing the player to play easily, engaging him/her with a visual experience in a comfortable position and environment.

11. Time management/ restriction

a) The game must be relatively slow and not require the use of many controls.

b) Encourage moderate amounts of time and controll/restricted time spent for playing games.

12. Repetition and a) Use repetitive elements to keep the children's interest.

rehearsal of skills

b) Repetition and practice are essential for the consolidation of learning.

c) If the players cannot overcome certain challenges, the game should provide extensive opportunities for them to rehearse and apply new skills. 


\begin{tabular}{l}
\hline Categories \\
$\begin{array}{l}\text { 13. Motivation and } \\
\text { engagement }\end{array}$ \\
b) $\begin{array}{l}\text { The game should transport the player to a psychological state } \\
\text { of flow. } \\
\text { There should be a clear goal to maintain the focus of the users } \\
\text { and engage them with the game. }\end{array}$ \\
c) Provide animated on-screen agents/characters to guide, \\
encourage or entertain children during the task. \\
d) The game should captivate players' interest to perform tasks on \\
their own initiative and not for the reward. \\
e) $\begin{array}{l}\text { Minimize the delay in response to engage the children with the } \\
\text { interaction, the game, and learning. }\end{array}$ \\
f) The game should offer a varying range of fun activities to \\
encourage learning and help maintain players' interest. \\
The game should be capable of estimating the cognitive abilities \\
of children by providing tasks that they are capable of performing. \\
Provide entertainment by embedding fun elements to maintain \\
children's interest and positive attitudes, promote intrinsic \\
motivation and allow children to take breaks from the main task.
\end{tabular}

14. Motor skill

15. Cognitive development a) Touch screen technology allows easy interactions for children whose coordination is yet to be fully developed.

b) The icons/images should be large and spaced appropriately to avoid wrong selections and to help users who have fine motor skill difficulties.

c) When manipulating objects in the game, it is more realistic to drag-drop objects to select and move them, rather than just clicking on them.

a) Simple game activities can trigger logical thinking.

b) In the decision-making process, players should be guided stepby-step.

c) Use the cause and effect paradigm and reverse actions in the game activities.

d) Avoid cluttering user's memories with complicated procedures for carrying out tasks.

e) The game should incorporate both sound and images to ensure effective learning process.

f) The games need to encourage children to recognize objects, actions and events around them.

g) Vocabulary used in the game should be modified according to the child's level of comprehension.

h) The game should apply the classification of objects based on similarities in shapes, colours and sizes.

i) The game should provide relevant play activities and be set at the right children's development level to suit their ability.

j) In order to apply problem-solving skills in the game, the same sequence in the real world must be followed. 


\begin{tabular}{l} 
Categories Design Guidelines \\
\hline k) $\begin{array}{l}\text { Dynamically link concrete representations and abstract concepts } \\
\text { to facilitate the learning of complex material. } \\
\text { 1) }\end{array}$ \\
Due to the difficulty involved in abstract thinking, the game \\
should use symbols and images to represent real-life situations. \\
m) $\begin{array}{l}\text { Children lack understanding on the concept of transformation, } \\
\text { and focus on the current state of the object rather than the } \\
\text { dynamic changes. }\end{array}$ \\
n) $\begin{array}{l}\text { The game should allow users to go back to a previous stage in the } \\
\text { game especially for users who have information processing and/ } \\
\text { or memory difficulties. }\end{array}$ \\
o) $\begin{array}{l}\text { The game should convey functional knowledge and provide the } \\
\text { players with opportunities to develop useful skills or practise } \\
\text { newly acquired skills. }\end{array}$ \\
p) $\begin{array}{l}\text { Use simple and memorable functions at the interface for } \\
\text { computational aids intended to support rapid decisions that occur } \\
\text { while on the move. }\end{array}$
\end{tabular}

\section{CONCLUSION}

The absence of suitable design guidelines for TSG in stimulating the cognitive ability of CSLD can influence the development of well-designed games. Yet, with guidance from a proper design guideline, the development of a TSG that meets the needs of the CSLD can be realized. In this study, a set of design guidelines for TSG targeting CSLD with the focus on cognitive stimulation is presented. This guideline can provide an important foundation for future research and should be useful for designers and researchers who plan to design serious games, particularly for the cognitive stimulation of CSLD.

However, there is one evident limitation to this study, which is the absence of the opinions of the CSLD. Involving CSLD in the user-testing process is important because designers and developers lack the experience of working with this population, therefore lacking real notions about their needs and capabilities (Tomé et al., 2014). Thus, future work should be focused on further refinement of the proposed guidelines by involving the CSLD in the testing stage of the concept prototypes of TSG for cognitive stimulation. This will increase the comprehensibility and completeness of the games, and further validate their acceptability in terms of being a usable design.

\section{ACKNOWLEDGMENT}

This research was funded by the Skim Latihan Akademik IPTA (SLAI) scholarship of the Ministry of Education, Malaysia. 


\section{REFERENCES}

Abdul Aziz, N. S., Wan Ahmad, W. F., \& Hashim, A. S. (2016). The design of mobile numerical application development lifecyle for children with autism. Jurnal Teknologi, 2, 77-83.

Ahmad, M., Rahim, L. A. B., \& Arshad, N. I. (2015). An analysis of educational games design frameworks from software engineering perspective. Journal of ICT, 14(2015), 123-151.

Ahmad Zaki, N. A., Tengku Wook, T. S. M., \& Ahmad, K. (2015). Analysis and classification of serious games for cognitive stimulation. The 5th International Conference on Electrical Engineering and Informatics 2015 (pp. 685-690).

Ahmad Zaki, N. A., Tengku Wook, T. S. M., \& Ahmad, K. (2017). Towards developing a therapeutic serious game design model for stimulating cognitive abilities: A case for children with speech and language delay. Advances in Intelligent Systems and Computing, 532, 259-269. https:// doi.org/10.1007/978-3-319-48517-1_23

Aziz, N. S. A., Ahmad, W. F. W., \& Zulkifli, J. (2015). User experience on numerical application between children with down syndrome and autism. Proceedings of CHI UX Indonesia 2015 (CHIuXiD 2015), 2631. https://doi.org/10.1145/2742032.2742036

Barak, B., \& Schiffman, L. G. (1981). Cognitive age: A nonchronological age variable. Advances in Consumer Research, 8, 602-606.

Barendregt, W., \& Bekker, M. M. (2004). Towards a framework for design guidelines for young children's computer games, 3166, 365-376. https://doi.org/10.1007/978-3-540-28643-1_47

Blumberg, F. C., \& Fisch, S. M. (2013). Introduction: Digital games as a context for cognitive development, learning, and developmental research. In F. C. Blumberg \& S. M. Fisch (Eds.), Digital games: A context for cognitive development. New directions for child and adolescent development (pp. 1-9). https://doi.org/10.1002/cad

Bonnier, C. (2008). Evaluation of early stimulation programs for enhancing brain development. Acta Paediatrica, International Journal of Paediatrics, 97(7), 853-858. https://doi.org/10.1111/j.1651-2227.2008. 00834.x 
Boot, W. R., Champion, M., Blakely, D. P., Wright, T., Souders, D. J., \& Charness, N. (2013). Video games as a means to reduce age-related cognitive decline: Attitudes, compliance, and effectiveness. Frontiers in Psychology, 4(February), 31. https://doi.org/10.3389/fpsyg.2013.00031

Buschmann, A., Jooss, B., Rupp, A., Dockter, S., Blaschtikowitz, H., \& Heggen, I. (2008). Children with developmental language delay at 24 months of age: Results of a diagnostic work-up. Developmental Medicine \& Child Neurology, 50, 223-229.

Carvalho, M. B., Bellotti, F., Hu, J., Hauge, J. B., Berta, R., Gloria, A. D., \& Rauterberg, M., (2015). Towards a service-oriented architecture framework for educational serious games. Proceedings - IEEE 15th International Conference on Advanced Learning Technologies: Advanced Technologies for Supporting Open Access to Formal and Informal Learning, ICALT 2015, 147-151. https://doi.org/10.1109/ ICALT.2015.145

Chiasson, S., \& Gutwin, C. (2005). Design principles for children's technology. Technical Report HCI-TR-05-02, 9. https://doi.org/10.1.1.83.5281

De La Guía, E., Lozano, M. D., \& Penichet, V. M. R. (2015). Educational games based on distributed and tangible user interfaces to stimulate cognitive abilities in children with ADHD. British Journal of Educational Technology, 46(3), 664-678. https://doi.org/10.1111/bjet.12165

de la Guia, E., Lozano, M. D., \& R. Penichet, V. M. (2013). Cognitive Rehabilitation based on collaborative and tangible computer games. Proceedings of the ICTs for Improving Patients Rehabilitation Research Techniques, 389-392. https://doi.org/10.4108/pervasive health.2013.252375

Devi, K. R., Sen, A. ., \& Hemachandran, K. (2012). A working framework for the user-centered design approach and a survey of the available methods. International Journal of Scientific and Research Publications, 2(4), 1-8.

Durango, I., Carrascosa, A., Gallud, J. A., \& Penichet, V. M. R. (2015). Using serious games to improve therapeutic goals in children with special needs. International Conference on Human-Computer Interaction with Mobile Devices and Services (pp. 743-749). https://doi. org/10.1145/2786567.2793696 
Gelderblom, H., \& Kotzé, P. (2008). Designing technology for young children: What we can learn from theories of cognitive development. Proceedings of the 2008 Annual Research Conference of the South African Institute of Computer Scientists and Information Technologists on IT Research in Developing Countries: Riding the Wave of Technology, (October), 66-75. https://doi.org/10.1145/1456659.1456668

Guía, E. De, Penichet, V. M. R., de la Guía, E., Lozana, M. D., \& Penichet, V. M. R. (2014). Tangible user interfaces applied to cognitive therapies. Proceedings of IUI 2014 Workshop: Interacting with Smart Objects.

Hackman, D. A., Farah, M. J., \& Meaney, M. J. (2010). Socioeconomic status and the brain: mechanistic insights from human and animal research. Nature Reviews. Neuroscience, 11(9), 651-659.

Hailpern, J., Harris, A., La Botz, R., Birman, B., \& Karahalios, K. (2012). Designing visualizations to facilitate multisyllabic speech with children with autism and speech delays. Designing Interactive Systems Conference, 126-135. https://doi.org/10.1145/2317956.2317977

Hawa, V. V., \& Spanoudis, G. (2014). Toddlers with delayed expressive language: An overview of the characteristics, risk factors and language outcomes. Research in Developmental Disabilities, 35(2), 400-407. https://doi.org/10.1016/j.ridd.2013.10.027

Herr, J. (2008). Theories principles and development child (6th ed.). Goodheart-Willcox.

Høiseth, M., Giannakos, M. N., \& Jaccheri, L. (2013). Research-derived guidelines for designing toddlers' healthcare games. CHI EA '13: CHI '13 Extended Abstracts on Human Factors in Computing Systems, 451456. https://doi.org/10.1145/2468356.2468436

Horne-Moyer, H. L., Moyer, B. H., Messer, D. C., \& Messer, E. S. (2014). The use of electronic games in therapy: A review with clinical implications. Current Psychiatry Reports, 16(12). https://doi.org/10.1007/s11920014-0520-6

Hotonu, A., Aldous, A., \& Schafer-Dreyer, R. (2011). Including children with speech and language delay in the foundation stage. London: A \& C Black 
Hoyer, W., \& Roodin, P. (2009). Adult development and ageing (6th ed.). Boston: McGraw-Hill.

Imbeault, F., Bouchard, B., \& Bouzouane, A. (2011). Serious games in cognitive training for alzheimer's patients. 2011 IEEE 1st International Conference on Serious Games and Applications for Health (SeGAH), $1-8$.

Jansen, R., Ceulemans, E., Grauwels, J., Maljaars, J., Zink, I., Steyaert, J., \& Noens, I. (2013). Young children with language difficulties: A dimensional approach to subgrouping. Research in Developmental Disabilities, 34(11), 4115-4124. https://doi.org/10.1016/j.ridd.2013. 08.028

Johnson, J. (2010). Designing with the mind in mind: Simple guide to understanding user interface design rules. Morgan Kaufmann. https:// doi.org/10.1016/B978-0-240-81176-5.X0001-9

Lafferty, A. E., Gray, S., \& Wilcox, M. J. (2005). Teaching alphabetic knowledge to pre-school children with developmental language delay and with typical language development. Child Language Teaching and Therapy, 21(3), 263-277.

Lányi, C. S., Brown, D. J., Standen, P., Lewis, J., \& Butkute, V. (2012). Results of user interface evaluation of serious games for students with intellectual disability. Acta Polytechnica Hungarica, 9(1), 225-245. https://doi.org/10.1007/978-3-642-14097-6_37

Law, J., Garrett, Z., \& Nye, C. (2003). Speech and language therapy interventions for children with primary speech and language delay or disorder. Cochrane Database of Systematic Reviews, (3).

Lawrence, R., \& Bateman, N. (2013). 12 minute consultation: An evidencebased approach to the management of a child with speech and language delay. Clinical Otolaryngology, 38(2), 148-153. https://doi. org/10.1111/coa.12082

Lazar, J., Feng, J. H. J., \& Hochheiser, H. (2010). Research methods in humancomputer interaction. Evaluation. https://doi.org/10.1002/asi.21187

Lieberman, D. a., Fisk, M. C., \& Biely, E. (2009). Digital games for young children aged three to six: From research to design. Computers in the Schools, 26(4), 299-313. https://doi.org/10.1080/07380560903360178 
Maguire, M. (2001). Methods to support human-centred design. International Journal of Human-Computer Studies, 55, 587-634. https://dx.doi. org/10.1006/ijhc.2001.0503

Malhi, P., Sidhu, M., \& Bharti, B. (2014). Early stimulation and language development of economically disadvantaged young children. Indian Journal of Pediatrics, 81(4), 333-338. https://doi.org/10.1007/s12098013-1154-0

Mariais, C., Michau, F., \& Pernin, J.-P. (2010). The use of game principles in the design of learning role-playing game scenarios. Proceedings of the 4th European Conference on Games Based Learning, 462-469.

McLaughlin, M. R. (2011). Speech and language delay in children. American Family Physician, 83(10), 1183-1188.

Nelson, H., Nygren, P., Walker, M., \& Panoscha, R. (2006). Screening for speech and language delay in preschool children: Systematic evidence review for the US Preventive Services Task Force. Pediatrics, 117(2).

Nielsen, J. (1993). Usability engineering. Morgan Kaufmann Pietquin $O$ and Beaufort R, 44(1/2002), 362. https://doi.org/10.1145/1508044.1508050

Parakh, M., Parakh, P., Bhansali, S., \& Gurjar, A. (2012). A clinicoepidemiologic study of neurologic associations and factors related to speech and language delay. National Journal of Community Medicine, 3(3), 518-523.

Rizzo, A., \& Kim, G. J. (2005). A SWOT analysis of the field of virtual reality rehabilitation and therapy. Presence, 14(2), 119-146. https://doi. org/10.1162/1054746053967094

Rogers, Y., Sharp, H., \& Preece, J. (2011). Interaction design: Beyond humancomputer interaction. ( $3^{\text {rd }}$ ed.) Vol. 11). Wiley.

Roungas, B., \& Dalpiaz, F. (2016). A model-driven framework for educational game design. Conference on Games and Learning Alliance (pp. 1-11). https://doi.org/10.1007/978-3-319-40216-1_1

Santrock, J. W. (2014). Essentials of life-span development (3rd ed.). New York: Mc Graw Hill. 
Schuit, M. Van Der, Segers, E., Balkom, H. Van, \& Verhoeven, L. (2011). Research in developmental disabilities. How cognitive factors affect language development in children with intellectual disabilities. Research in Developmental Disabilities, 32(5), 1884-1894. https://doi. org/10.1016/j.ridd.2011.03.015

Shaffer, D. R., \& Kipp, K. (2014). Developmental psychology: Childhood \& adolescence (9th ed.). Belmont: Cengage Learning.

Shetty, P. (2012). Speech and language delay in children: A review and the role of a pediatric dentist. Journal of Indian Society of Pedodontics and Preventive Dentistry, 30(2), 103-108. https://doi.org/10.4103/09704388.99979

Singleton, N. C., \& Shulman, B. B. (2014). Language development: Foundations, processes, and clinical applications (2nd ed.). William Brottmiller.

Straker, L., Abbott, R., Collins, R., \& Campbell, A. (2014). Evidence-based guidelines for wise use of electronic games by children. Ergonomics, $57(4), 471-489$.

Szczesna, A., Tomaszek, M., \& Wieteska, A. (2012). The methodology of designing serious games for children and adolescents focused on psychology goals. Lecture Notes in Computer Science, 7339 LNBI, 245-255.

Tengku Wook, T. S. M., \& Salim, S. S. (2013). Guideline for the graphic design of web application for children's interface. TELCOMNIKA, 11(6), 3130-3133.

Tomé, R., Pereira, J., Oliveira, M., Tom, R. M., Tomé, R., Pereira, J., \& Oliveira, M. (2014). Using serious games for cognitive disabilities. Serious Games Development and Applications, 8778, 34-47.

Tran, P., \& Subrahmanyam, K. (2013). Evidence-based guidelines for the informal use of computers by children to promote the development of academic, cognitive and social skills. Ergonomics, 56(9), 37-41. https://doi.org/10.1080/00140139.2013.820843 
Vasconcelos, A., Silva, P. A., Caseiro, J. J., Nunes, F., F.Teixeira, L., Teixeira, L. F., \& Teixeira, F. (2012). Designing tablet-based games for seniors: The example of CogniPlay, a cognitive gaming platform. Proceedings of the 4th International Conference on Fun and Games, 3, 1-10. https:// doi.org/10.1145/2367616.2367617

Wrzesien, M., Raya, M. A., Botella, C., Burkhardt, J., Breton-López, J., \& Ortega, A. R. (2014). A pilot evaluation of a therapeutic game applied to small animal phobia treatment. Serious Games Development and Applications (Vol. 8778, pp. 10-20). https://doi.org/10.1007/978-3319-11623-5_2 